Intecoms: Journal of Information Technology and Computer Science

Volume 2 Nomor 2, Desember 2019

e-ISSN : 2614-1574

p-ISSN : 2621-3249

DOI : https://doi.org/10.31539/intecoms.v2i2.939

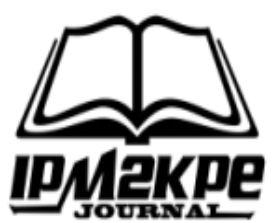

\title{
METODE COUPLE LINEAR CONGRUENTIAL GENERATOR (CLCG) UNTUK UJIAN SEKOLAH BERBASIS WEB
}

\section{COUPLE LINEAR CONGRUENTIAL GENERATOR (CLCG) METHOD FOR WEB-BASED SCHOOL EXAMS}

\author{
Cendra Wadisman ${ }^{1}$, Irohito Nozomi ${ }^{2}$ \\ Universitas Putra Indonesia "YPTK" Padang 1,2 \\ cendra_wadisman@upiyptk.ac.id ${ }^{1}$
}

\begin{abstract}
IN SMA N 2 Kota Pariaman school exams still use the answer sheet media at the time of publication. After the exam is complete the answer sheet of the exam will also be corrected by the subject teacher who will discuss the students' problems, each student also receives the same question. SMA N 2 Kota Pariaman was chosen as a research location because this school has not used the Application during school exams, it is easy to achieve and economical. The application to be used can randomize randomly so that exam questions can be varied and dynamic. With the application of the application that is expected to carry out school examinations will be better and obtained optimally by students, teachers, school management and parents / guardians of students. For this reason, the authors will conduct research consisting of the design of Computer Based Test applications using the Coupled Linear Congruential Generator (CLCG) method. The development of the Computer Based Test (CBT) model by using a Coupled Linear Congruent Generator (CLCG) can prevent the questioning of questions for students. CLCG is a random number generator based on the Linear Congruent Generator (LCG). CLCG uses the xj matrix to get random numbers. organized by rows and columns. The matrix prefers a range of numbers and has no arithmetic relationship between its elements. The matrix will have different row and column addresses. The value of the elements of the matrix obtained from the process with the Linear Congruent Generator to get as many random numbers as is done. CBT is one way of overcoming questions in each student. The use of LCG in the matrix value element can have a more complicated random pattern. Reducing the question answer key by entering the answer key time after the exam is finished. Languages supported using the CLCG method can optimize student abilities and reduce the level of cheating. Reducing the question answer key by entering the answer key time after the exam is finished.
\end{abstract}

Keywords: CBT Appliaction, Couple Linear Congruential Generator, Linear Congruential Generator, Random Number, School Exam.

\begin{abstract}
ABSTRAK
Pada SMAN 2 Kota Pariaman ujian sekolah masih menggunakan media kertas sebagai lembar jawaban seperti pada umumnya. Setelah ujian selesai lembar jawaban ujian juga akan dikoreksi oleh guru mata pelajaran yang kemungkinan akan terjadi kesalahan yang dapat merugikan peserta didik, setiap siswa juga mendapatkan soal yang sama. SMA N 2 Kota pariaman dipilih sebagai lokasi penelitian karena sekolah tersebut belum menggunakan Aplikasi saat ujian sekolah, mudah dijangkau dan ekonomis. Aplikasi yang akan di bangun dapat melakukan pengacakan soal secara random sehingga soal-soal ujian yang keluar dapat bervariasi dan dinamis. Dengan diterapkannya aplikasi tersebut diharapkan pelaksanaan ujian sekolah akan semakin baik dan hasilnya dapat diperoleh dengan optimal oleh siswa, guru, manajemen sekolah dan orang tua/wali siswa. Oleh karena alasan tersebut maka penulis akan melakukan penelitian berupa rancang bangun aplikasi Computer Based Test menggunakan metode Coupled Linear Congruential Generator (CLCG). Pengembangan model Computer Based Test (CBT) dengan menerapkan Coupled Linear Congruent Generators (CLCG) dapat mencegah kesamaan soal pada siswa. CLCG merupakan pembangkit bilangan acak berbasis Linear Congruent Generators (LCG). CLCG memanfaatkan matriki x j untuk mendapatkan bilangan acak. yang disusun menurut baris dan kolom. Matrik hanyalah sekedar jajaran sekumpulan bilangan dan tidak memiliki hubungan aritmetis antar
\end{abstract}


elemen-elemennya. Matrik akan memiliki alamat baris dan kolom yang berbeda-beda. Nilai elemenelemen dari matrik didapatkan dari proses dengan Linear Congruent Generators untuk mendapatkanbilangan acak sebanyak soal yang dikerjakan. Sistem pengacakan soal pada CBT merupakan salah satu cara pencegahan kesamaan soal dalam pelaksanaan ujian untuk masing-masing siswa. Penggunaan LCG pada nilai elemen matrik dapat memilik pola acak yang lebih rumit. Mengurangi kebocoran kunci jawaban soal dengan cara waktu input kunci jawaban dilakukan setelah ujian selesai . Luaran yang ditargetkan Dengan menggunakan metode CLCG dapat mengoptimalkan kemampuan siswa dan mengurangi tingkat kecurangan. Mengurangi kebocoran kunci jawaban soal dengan cara waktu input kunci jawaban dilakukan setelah ujian selesai.

Kata Kunci: Aplikasi CBT, Couple Linear Congruential Generator, Linear Congruential Generator, Bilangan Acak, Ujian Sekolah.

\section{PENDAHULUAN}

Pendidikan merupakan hal penting yang harus dimiliki oleh setiap orang. Kualitas pendidikan dapat diketahui dengan melalui pelaksanaan ujian untuk mengetahui pencapaian kemampuan dan keberhasilan dalam memahami bidang studi yang ditempuhnya (Ichsan, 2014). Seiring perkembangan teknologi informasi dan komunikasi sistem ujian sudah tidak lagi menggunakan media konvensional melainkan sudah secara komputerisasi. Pelaksaan ujian secara konvensional kurang efektif dan kurang efisien karena membutuhkan biaya yang besar untuk mencetak soal, membutuhkan waktu yang lama untuk distribusi soal dan pemeriksaan jawaban masih secara manual. Selain itu menurut Nasution (2013) menyatakan bahwa pelaksanaan ujian secara konvensional rentan terhadap kebocoran soal yang akan diajukan sebelum ujian dan kecurangan yang dilakukan seperti mencontek jawaban teman. Dengan adanya ujian secara komputerisasi akan memiliki keunggulan berupa pengurangan biaya dan waktu yang dapat menutup kekurangan pada pelaksanaan ujian secara konvensional.

Ujian Sekolah adalah salah satu syarat yang harus dilalui peserta didik untuk mengukur kemampuan yang telah dicapai selama pembelajaran, biasanya ujian dilakukan 2 kali setiap tahunnya. Ujian di SMA N 2 Kota Pariaman saat ini masih menggunakan media kertas sebagai lembar jawaban seperti pada umumnya. Dengan demikian sekolah harus mengeluarkan biaya untuk mencetak lembar soal ujian bagi seluruh siswa yang akan melaksanakan ujian dan menyediakan kertas jawaban. Dengan keadaan seperti itu sekolah akan menganggarkan biaya setiap tahunnya untuk melaksanakan ujian. Setelah ujian selesai lembar jawaban ujian juga akan dikoreksi oleh guru mata pelajaran yang kemungkinan akan terjadi kesalahan yang dapat merugikan peserta didik. Masalah di atas bisa diatasi apabila sekolah memiliki suatu aplikasi yang didalamnya terdapat sistem yang fungsi dan tujuannya sama dengan melaksanakan ujian secara konvesional tetapi dalam bentuk aplikasi.

Aplikasi yang dapat melakukan pengacakan soal pada secara random sehingga soal-soal ujian yang keluar dapat bervariasi dan dinamis. Dengan diterapkannya aplikasi tersebut diharapkan pelaksanaan ujian sekolah akan semakin baik dan hasilnya dapat diperoleh dengan optimal oleh siswa, guru, manajemen sekolah dan orang tua/wali siswa. Oleh karena alasan tersebut maka penulis akan melakukan penelitian berupa rancang bangun aplikasi Computer Based Test menggunakan metode Coupled Linear Congruential Generator (CLCG). Menghasilkan urutan nomor secara acak 
telah menjadi masalah minat jangka panjang bagi praktisi dan peneliti simulasi komputer. Biantara, et.al., (2015) dalam penelitian nya tentang modifikasi metode linear congruential generator untuk optimalisasi hasil acak menggunakan matrik untuk mengambil nilai elemen-elemen dari alamat baris dan kolom. Untuk mendapatkan alamat baris dan kolom menggunakan persamaan Linear Cogruential Generator.

Pada penelitian yang dilakukan Hangga A dan Hendro Eko Prabowo, (2016) juga melakukan Modifikasi Linear Congruential Generator untuk system pengacakan soal pada Computer Based Test (CBT) menggunakan perbedaan variable yang mewakili jumlah soal tes dan pembatasan variable serta kombinasi deret bilangan koprima, prima dan Fibonacci digunakan sebagai manipulasi pembatasan variabel. Meilani, B.D., dkk., (2016) membuat aplikasi random bank soal ujian nasional sekolah dasar menggunakan metode Linear Congruential Generator (LCG) yang mengambil nilai acak awal dari 2 digit angka terakhir no ujian peserta. Ramadhan., K et al, (2015) pernah melakukan penelitian yang berjudul Game Edukasi Tebak Gambar Benedera Negara Menggunakan Metode Linear Congruential Generator (LCG). Game tersebut dibuat menggunakan Eclips diantu plugin ADT dan android SDK Tools yang menggunakan gambar sebagai soal acak bendera dari Negara. Sofyan (2016) menerapkan Linear Congruential Generator (LCG) pada permainan ken ken yang menggunakan bahasa pemrograman Microsoft Visual Basic .Net 2010.

Menurut Meilani et al, (2016) bilangan acak atau random adalah sebuah bilangan yang telah diproses untuk menghasilkan bilangan secara berurutan dan tidak menghasilkan bilangan yang sama. Proses pembangkitan bilangan random menggunakan komputer disebut Pseudorandom number generator (PRNG). Berikut ini beberapa pembangkit bilangan acak semu: 1) linear Congruent Generators (LCG), 2) lagged Fibonacci Generators, 3) linear Feedback shift Registers, 4) generalised Feedback shift Registers, 5) mersenne Twister.

Linear Congruent Generators (LCG) Merupakan pseudorandom number generator yang telah digunakan dalam aplikasi komputer. LCG ditemukan oleh D.H Lehmer. Linear Congruent Method (LCM) merupakan metode yang memanfaatkan model linear untuk menghasilkan bilangan secara acak yang didefinisikan dengan (1):

$$
x_{n+1}=\left(\left(a \times x_{n}\right)+b\right) \bmod m
$$

Keterangan:

$$
\begin{array}{ll}
x_{n+1} & =\text { Bilangan acak ke } \mathrm{n} \text { dari } \\
& \text { deretnya } \\
x_{n} & =\text { Bilangan acak sebelumnya } \\
a & =\text { Faktor pengali } \\
b & =\text { Penambah } \\
m & =\text { Jumlah Soal } \\
n & =0,1,2,3, \ldots \text { dan seterusnya }
\end{array}
$$

LCG memiliki relative penuh jika dan hanya jika: 1) $b$ relative prima terhadap $m$, 2) $a-1$ dapat dibagi dengan factor prima dari $m, 3) a-1$ adalah kelipatan 4 jika $m$ adalah kelipatan 4

Matrik menurut Biantara et al, (2015) Matrik merupakan susunan bilangan yang disusun dalam baris dan kolom seperti yang ditunjukkan pada Gambar 1 


$\left[\begin{array}{ccccc}a 11 & a 12 & a 13 & a 14 & a 15 \\ . . & . . & . . & . . & . . \\ . . & . . & . . & . . & . . \\ a i 1 & a i 2 & a i 3 & a i 4 & a i 5\end{array}\right]$

Gambar. 1 Notasi Matrik

Nilai dari elemen matrik A yang terlihat di Gambar 1 merupakan bilangan sebanyak jumlah soal. Nilai dari elemen-elemen tersebut digunakan untuk pengacakan soal dengan metode Coupled Linear Congruential Generator (CLCG). Jumlah kolom matrik yang digunakan sebanyak 5 sedangkan jumlah baris yang digunakan yaitu jumlah soal dibagi jumlah kolom, sehigga jumlah baris 4 .

\section{Coupled Linear Congruent} Generators (CLCG). Menurut Biantara, dkk, (2015) Merupakan sebuah pembangkit bilangan acak semu dengan menggabungkan dua persamaan linear berbasis metode LCG. Model matematis CLCG dapat dihitung dengan menggunakan persamaan (2) :

$$
\begin{aligned}
& x_{n+1}=\left(\left(a_{1} \mathrm{x} x_{n}\right)+b_{1}\right) \bmod m x \\
& y_{n+1}=\left(\left(a_{2} \mathrm{y} y_{n}\right)+b_{1}\right) \bmod m y
\end{aligned}
$$

Keterangan:

$x_{n+1}=$ Bilangan acak $x$ ke $\mathrm{n}$ dari deretnya $\quad y_{n+1} \quad=$ Bilangan acak $y$ ke $\mathrm{n}$ dari deretnya $x_{n}=$ Bilangan acak $x$ sebelumnya $y_{n} \quad=$ Bilangan acak $y$ sebelumnya $a=$ Faktor pengali $b=$ penambah

$$
\begin{aligned}
m x & =\text { Jumlah Baris } \\
\text { my } & =\text { Jumlah kolom } \\
n & =0,1,2,3, \ldots \text { dan seterusnya } \\
& \text { Berdasarkan hasil persamaan }
\end{aligned}
$$
diatas maka akan didapatkan deret bilangan acak yang akan diubah ke dalam orde matrik. Orde didapatkan dari hasil perhitungan modulus terhadap jumlah baris sehingga didapatkan persamaan (3) :

$$
\mathrm{M}_{(\mathrm{x}, 0)}=x_{n+1} \bmod i
$$

Orde didapatkan dari hasil perhitungan modulus terhadap jumlah kolom dengan sehingga didapatkan persamaan (4) :

$$
\mathrm{M}_{(0, \mathrm{y})}=y_{n+1} \bmod j
$$

Model matematis untuk hasil bilangan acak dengan menggunakan matrik baru dapat dihitung dengan menggunakan persamaan (5) :

$\mathrm{M}_{\mathrm{n}}=\mathrm{M}\left[x_{n+1} \bmod i\right]\left[y_{n+1} \bmod j\right]$

Keterangan:

$\mathrm{M}_{\mathrm{n}} \quad$ = Hasil bilangan acak ke-n dari deretnya

$x_{n+1}=$ Bilangan acak $x$ ke $\mathrm{n}$ dari

deretnya

$y_{n+1} \quad=$ Bilangan acak $y$ ke $\mathrm{n}$ dari deretnya

$i \quad=$ Baris Matrik

$j \quad=$ Kolom Matrik

$n=0,1,2,3, \ldots$ dan seterusnya

Dengan menggunakan alamat orde matrik dapat dilakukan pengambilan nilai dengan menyesuaikan alamat orde matrik secara urut berdasarkan hasil acak dari matrik.

E-Learning menurut Martono \& Nurhayati merupakan pembelajaran elektronik cara baru dalam proses belajar mengajar menggunakan media elektronik khususnya internet sebagai sistem pembelajarannya. Melalui ELearning, adalah mungkin bagi pelajar untuk belajar menggunakan komputer di tempat mereka sendiri, daripada secara fisik menghadiri kelas untuk belajar. Karena istilah e-learning mengandung arti yang sangat luas, banyak ahli mendefinisikan e-learning dari berbagai perspektif. e-Learning mengacu pada penggunaan teknologi internet untuk mengirim serangkaian solusi yang dapat meningkatkan pengetahuan dan keterampilan. Dari definisi ini, dapat disimpulkan bahwa e-learning adalah pembebasan konten pembelajaran didistribusikan secara elektronik melalui web (Internet dan / atau 
Internet) atau melalui CD / DVD (offline) dan dilengkapi dengan evaluasi komponen di dalam.

Berdasarkan teknologi yang digunakan, elearning dapat dibagi menjadi basis teknologi termasuk: 1) CBT (Pelatihan berbasis komputer), 2) LMS (Sistem

Pembelajaran), 3) Manajemen

Pembelajaran Berbasis Web. Computer Based Test (CBT). Menurut Bahri, dkk (2012) merupakan suatu penilaian berbasis komputer, juga dikenal sebagai Computer Based Test (CBT), meliputi penilaian, pengujian dengan menggunakan komputer adalah suatu metode pengelolaan dan pelaksanaan tes yang dilakukan secara elektronik kemudian dicatat, dinilai, atau keduanya. Seperti namanya, Penilaian Berbasis Komputer (PBK) memanfaatkan komputer atau perangkat elektronik setara seperti ponsel atau PDA, sistem PBK memungkinkan pendidik dan pelatih untuk menulis jadwal, menyampaikan laporan tentang survey, kuis, tes dan ujian (Ambiyar, et $a l, 2019)$.

PHP merupakan singkatan dari "PHP: Hypertext Preprocessor", yang merupakan bahasa scripting yang dilekatkan pada Bahasa Marking HyperText (HTML). Kebanyakan sintaks bahasa mirip dengan C, Java, dan Perl, PHP ditambah beberapa fungsi spesifik. Tujuan utamanya adalah penggunaan bahasa adalah untuk memungkinkan pengembang web tulis halaman web dinamis.

$$
\text { MySQL merupakan My }
$$

Structured Query Language (MySQL) adalah program manajemen basis data atau pabrikan dan sering disebut Manajemen Database Sistem (DBMS). Ini adalah sifat open source DBMS. MySQL juga merupakan basis data yang diakses jaringan program, sehingga dapat digunakan untuk multiuser aplikasi (banyak pengguna). Keuntungan lain MySQL menggunakan bahasa query (permintaan) SQL standar. SQL adalah bahasa query terstruktur, SQL telah distandarisasi untuk semua program yang diakses database.

\section{METODE PENELITAN}

Penelitian ini menggunakan metode pengacakan Coupled Linear Congruent Generators(CLCG) agar mendapatkan kombinasi soal ujian pada siswa. Metode CLCG menggunakan matrik yang digunakan untuk menentukan hasil akhir pengacakan setelah melalui proses persamaan LCG.

\section{Linear}

Congruent

Generatorsdapat digambarkan dengan flowchart:

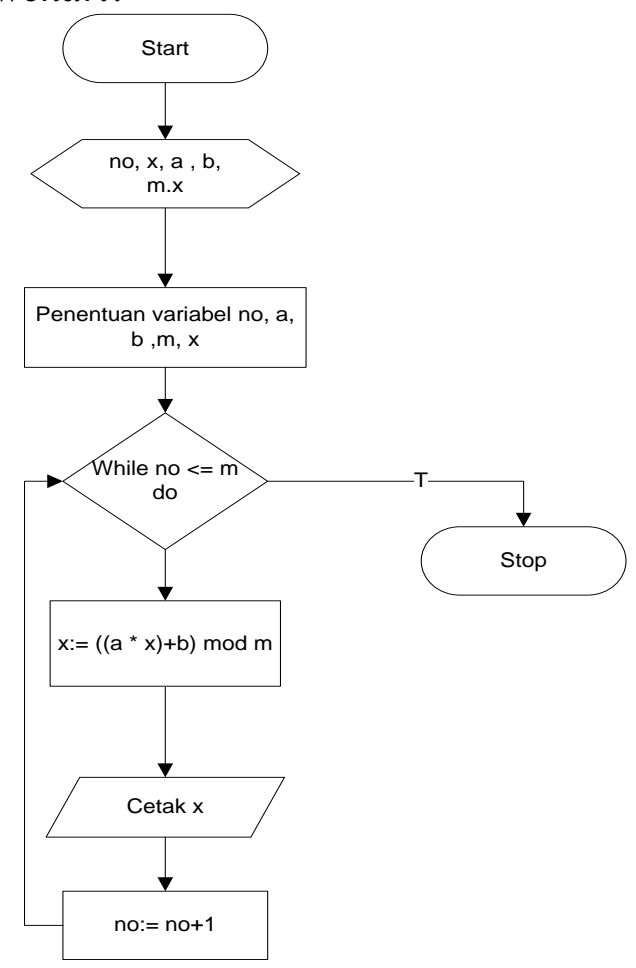

\section{Gambar. 2 Flowchart Linear Congruent Generators}

Proses pembangkitan bilangan random untuk mengacak soal menggunakan LCG dilakukan dengan empat tahap: 1) menentukan jumlah soal yang diacak $(m), 2)$ penentuan nilai variabel faktor pengali (a), 3) penentuan 
variabel penambah (b), 4) perhitungan dengan menggunakan persamaan (1).

Untuk mendapatkan nilai acak yang lebih rumit, LCG di modifikasi sehingga hasil yang didapatkan berupa alamat pada matrik.CLCG dapat digambarkan dengan flowchart berikut:

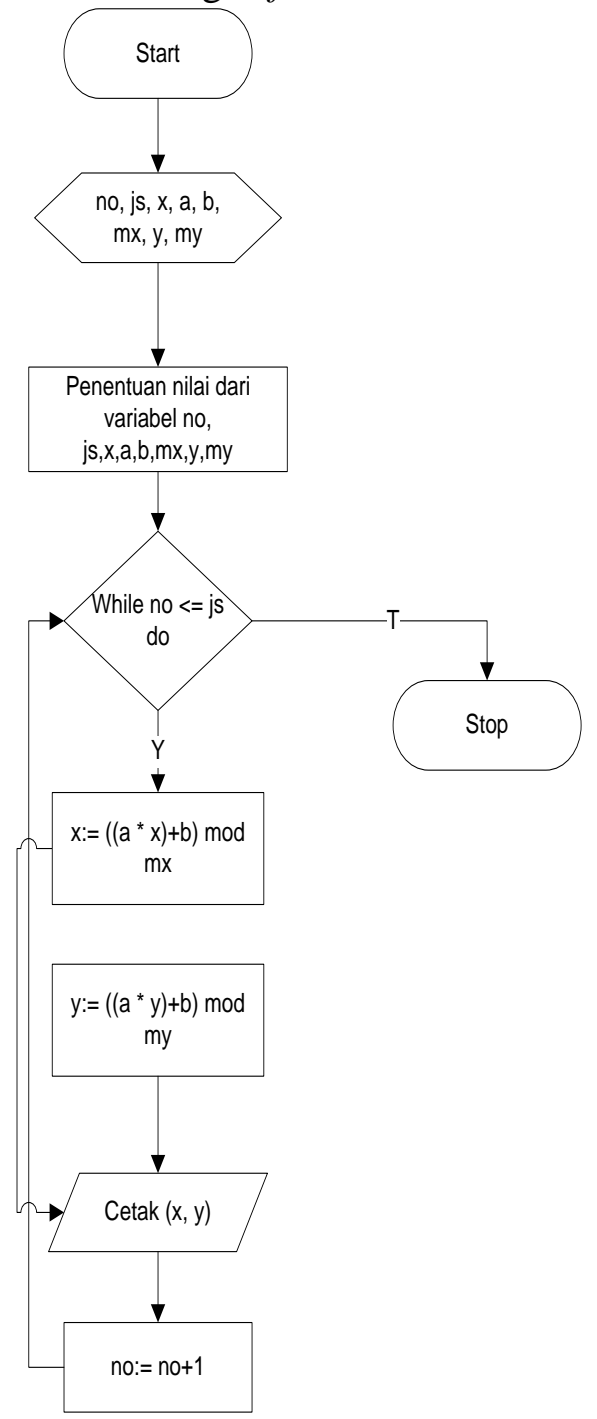

Gambar. 3 Flowchart Coupled Linear Congruent Generators

Proses pembangkitan bilangan random untuk mengacak soal menggunakan CLCG dilakukan dengan tahapan berikut:

1. Menentukan jumlah soal yang diacak (m)

2. Menentukan nilai variabel faktor pengali (a).

3. Menentukan variabel penambah (b).
4. Jumlah baris dan kolom matrik A dimana jumlah elemennya sesuai dengan jumlah soal yang diacak.

5. Perhitungan variabel dengan tahap yang sama seperti LCG dan harus diulang 2 kali.

6. Perhitungan bilangan acak dan sesuai dengan persamaan (2).

7. Pembentukan matrik Mn dan penyesuaian orde matrik dengan matrik sesuai dengan persamaan (46) merupakan tahap akhir dari pengacakan soal dengan metode CLCG.

\section{HASIL DAN PEMBAHASAN}

Hasil pola pengacakan tersebut didapatkan dengan menghitung hasil acak dari setiap deret menggunakan metode CLCG. Tahapan CLCG untuk mengacak soal ujian sekolah: 1) menentukan jumlah soal yang diacak $(\mathrm{m}), 2)$ menentukan nilai variabel faktor pengali (a), 3) menentukan variabel penambah (b), 4) jumlah baris dan kolom matrik A dimana jumlah elemennya sesuai dengan jumlah soal yang diacak.Penentuan nilai pada tiap tahapan seperti tabel 1 .

Tabel. 1 Nilai Variabel tiap tahapan

\begin{tabular}{cccccc}
\hline No & Jumlah Soal $(\mathrm{m})$ & $\mathrm{a}$ & $\mathrm{b}$ & $\mathrm{mx}$ & $\mathrm{my}$ \\
\hline 1 & 20 & 21 & 17 & 4 & 5 \\
\hline
\end{tabular}

Untuk member nilai pada elemenelemen matriks digunakan metode LCG seperti pada tabel 2 .

Tabel. 2 Nilai Elemen Matrik

\begin{tabular}{lll}
\hline Alamat & \multicolumn{1}{c}{ Persamaan } & Hasil \\
\hline 1.1 & $((21 * 8)+17) \bmod 20$ & 5 \\
1.2 & $((21 * 5)+17) \bmod 20$ & 2 \\
1.3 & $((21 * 2)+17) \bmod 20$ & 19 \\
1.4 & $((21 * 19)+17) \bmod 20$ & 16 \\
1.5 & $((21 * 16)+17) \bmod 20$ & 13 \\
2.1 & $((21 * 13)+17) \bmod 20$ & 10 \\
2.2 & $((21 * 10)+17) \bmod 20$ & 7 \\
2.3 & $((21 * 7)+17) \bmod 20$ & 4 \\
2.4 & $((21 * 4)+17) \bmod 20$ & 1 \\
\hline
\end{tabular}




\begin{tabular}{lll}
\hline 2.5 & $((21 * 1)+17) \bmod 20$ & 18 \\
3.1 & $((21 * 18)+17) \bmod 20$ & 15 \\
3.2 & $((21 * 15)+17) \bmod 20$ & 12 \\
3.3 & $((21 * 12)+17) \bmod 20$ & 9 \\
3.4 & $((21 * 9)+17) \bmod 20$ & 6 \\
3.5 & $((21 * 6)+17) \bmod 20$ & 3 \\
4.1 & $((21 * 3)+17) \bmod 20$ & 20 \\
4.2 & $((21 * 0)+17) \bmod 20$ & 17 \\
4.3 & $((21 * 17)+17) \bmod 20$ & 14 \\
4.4 & $((21 * 14)+17) \bmod 20$ & 11 \\
4.5 & $((21 * 11)+17) \bmod 20$ & 8 \\
\hline
\end{tabular}

Nilai dari alamat matrik yang dihasilkan dengan menggunakan metode LCG dari tabel 2 dapat dilihat pada gambar 4.

$$
\left[\begin{array}{ccccc}
5 & 2 & 19 & 16 & 13 \\
10 & 7 & 4 & 1 & 18 \\
15 & 12 & 9 & 6 & 3 \\
20 & 17 & 14 & 11 & 8
\end{array}\right]
$$

\section{Gambar. 4 Nilai Matrik}

Perhitungan bilangan acak dan sesuai dengan persamaan (3) pada tabel 3 dan persamaan (4) pada tabel 4.

Tabel. 4 Rumus Persamaan 3

\begin{tabular}{lcl}
\hline No & Persamaan $(\mathrm{x})$ & Hasil $(\mathrm{x})$ \\
\hline 1 & $((21 * 1)+17) \bmod 4$ & 2 \\
2 & $((21 * 2)+17) \bmod 4$ & 3 \\
3 & $((21 * 3)+17) \bmod 4$ & 0 jadi 4 \\
4 & $((21 * 0)+17) \bmod 4$ & 1 \\
5 & $((21 * 1)+17) \bmod 4$ & 2 \\
6 & $((21 * 2)+17) \bmod 4$ & 3 \\
7 & $((21 * 3)+17) \bmod 4$ & 0 jadi 4 \\
8 & $((21 * 0)+17) \bmod 4$ & 1 \\
9 & $((21 * 1)+17) \bmod 4$ & 2 \\
10 & $((21 * 2)+17) \bmod 4$ & 3 \\
11 & $((21 * 3)+17) \bmod 4$ & 0 jadi 4 \\
12 & $((21 * 0)+17) \bmod 4$ & 1 \\
13 & $((21 * 1)+17) \bmod 4$ & 2 \\
14 & $((21 * 2)+17) \bmod 4$ & 3 \\
15 & $((21 * 3)+17) \bmod 4$ & 0 jadi 4 \\
16 & $((21 * 0)+17) \bmod 4$ & 1 \\
17 & $((21 * 1)+17) \bmod 4$ & 2 \\
18 & $((21 * 2)+17) \bmod 4$ & 3 \\
19 & $((21 * 3)+17) \bmod 4$ & 0 jadi 4 \\
20 & $((21 * 0)+17) \bmod 4$ & 1 \\
\hline
\end{tabular}

Tabel. 5 Rumus Persamaan 4

\begin{tabular}{lcl}
\hline No & Persamaan $(\mathrm{y})$ & Hasil $(\mathrm{y})$ \\
\hline 1 & $((21 * 5)+17) \bmod 5$ & 2 \\
2 & $((21 * 2)+17) \bmod 5$ & 4 \\
3 & $((21 * 4)+17) \bmod 5$ & 1 \\
4 & $((21 * 1)+17) \bmod 5$ & 3 \\
5 & $((21 * 3)+17) \bmod 5$ & 0 jadi 5 \\
6 & $((21 * 0)+17) \bmod 5$ & 2 \\
7 & $((21 * 2)+17) \bmod 5$ & 4 \\
8 & $((21 * 4)+17) \bmod 5$ & 1 \\
9 & $((21 * 1)+17) \bmod 5$ & 3 \\
10 & $((21 * 3)+17) \bmod 5$ & 0 jadi 5 \\
11 & $((21 * 0)+17) \bmod 5$ & 2 \\
12 & $((21 * 2)+17) \bmod 5$ & 4 \\
13 & $((21 * 4)+17) \bmod 5$ & 1 \\
14 & $((21 * 1)+17) \bmod 5$ & 3 \\
15 & $((21 * 3)+17) \bmod 5$ & 0 jadi 5 \\
16 & $((21 * 0)+17) \bmod 5$ & 2 \\
17 & $((21 * 2)+17) \bmod 5$ & 4 \\
18 & $((21 * 4)+17) \bmod 5$ & 1 \\
19 & $((21 * 1)+17) \bmod 5$ & 3 \\
20 & $((21 * 3)+17) \bmod 5$ & 0 jadi 5 \\
\hline
\end{tabular}

Setelah perhitungan tersebut selesai didapatkan alamat dan nilai dari pengacakan soal tersebut seperti pada tabel 6 .

Tabel. 6 Hasil CLCG

\begin{tabular}{lcl}
\hline No & Alamat $(\mathrm{x}, \mathrm{y})$ & Hasil $(\mathrm{x}, \mathrm{y})$ \\
\hline 1 & $(2,2)$ & 7 \\
2 & $(3,4)$ & 6 \\
3 & $(4,1)$ & 20 \\
4 & $(1,3)$ & 19 \\
5 & $(2,5)$ & 18 \\
6 & $(3,2)$ & 12 \\
7 & $(4,4)$ & 11 \\
8 & $(1,1)$ & 5 \\
9 & $(2,3)$ & 4 \\
10 & $(3,5)$ & 3 \\
11 & $(4,2)$ & 17 \\
12 & $(1,4)$ & 16 \\
13 & $(2,1)$ & 10 \\
14 & $(3,3)$ & 9 \\
15 & $(4,5)$ & 8 \\
16 & $(1,2)$ & 2 \\
17 & $(2,4)$ & 1 \\
18 & $(3,1)$ & 15 \\
19 & $(4,3)$ & 14 \\
20 & $(1,5)$ & 13 \\
\hline
\end{tabular}

Berdasarkan tabel 5 dapat dilihat hasil dari peneapan CLCG berupa bilangan acak yang didapatkan dari nilai elemen-elemen matrik sesuai alamat 
yang dihasilkan dari persamaan yang diterapkan.

Pelaksanaan ujian berbasis komputer mempunyai beberapa keunggulan yaitu menghemat biaya cetak soal ujian, menghemat waktu distribusi soal dan pemeriksaan jawaban dilakukan secara otomatis sehingga hasil ujian dapat langsung dilihat oleh siswa. Keunggulan yang dimiliki ujian berbasis komputer tidak sepenuhnya sempurna tanpa celah sehingga masih terdapat kelemahan dalam pelaksanaannya yaitu siswa dapat mengakses sumber informasi pendukung secara online dan menggunakan alat bantu komputer yang tidak diperbolehkan saat ujian tanpa diketahui oleh pengawas untuk memperoleh jawaban (Ichsan, 2014).

Pengacakan dilakukan dengan bantuan algoritma pembangkit bilangan acak semu (pseudorandom number generator) untuk menghasilkan deret bilangan acak. Metode yang paling terkenal dalam pembangkit bilangan acak semu adalah metode Linear Congruential Generator, tetapi hasil dari metode tersebut masih terlihat periodik sehingga harus diberikan nilai variabel yang selalu berubah-ubah untuk mengatasi keperiodikan hasil acak yang terjadi (Munthe, 2014). Keperiodikan tersebut dapat menyebabkan soal yang diacak memiliki nomor yang sama terhadap siswa yang berada disekitarnya. Selain itu, metode Linear Congruential Generator mempunyai kelemahan yaitu jika sebuah deret bilangan acak yang dihasilkan diketahui, maka parameter dan modulus dari metode tersebut dapat diuraikan sehingga akan menyebabkan hasil acak menjadi tidak aman dan dapat diketahui hasil pola pengacakan (Katti, 2010).

\section{SIMPULAN}

Untuk mendapatkan nilai acak yang lebih rumit dapat menerapkan algoritma LCG pada saat memberi nilai pada elemen-elemen pada matrik sesuai alamat matrik tersebut. Penggunaan CoupledLinear Congruential Generatoryang dikombinaasikan dengan penggunaan LCG pada pemberian nilai elemen matrik memiliki pola pengacakan yang lebih rumit dibandingkan metode Linear Congruential Generator. Pola pengacakan dipengaruhi oleh beberapa factor, seperti susunan nilai matrik, nilai-variabel yang sesuai ketentuan. Semakin banyak kombinasi nilai variabel dan maka semakin banyak pengacakan yang dihasilkan. Selain itu, semakin banyak jumlah soal yang menghasilkan ordo matrik yang lebih banyak serta nilai variabel maka semakin rumit pola pengacakan yang dihasilkan. Karena menggunakan matrik sehingga hanya pada kondisi tertentu dimana jumlah soal yang diacak harus sama dengan jumlah elemen yang terdapat dalam matrik.

Hasil yang didapatkan dengan menerapkan Coupled Linear Congruential generators (CLCG) dan menerapkan Linear Congruential Generator (LCG) pada matrik untuk memberi nilai elemen-elemen sesuai alamat baris dan kolom memiliki pola pengacakan yang dipengaruhi pola matrik yang dihasilkan. Semakin banyak jumlah soal akan mempengaruhi ordo matrik yang dihasilkan. 
DAFTAR PUSTAKA

Ambiyar, H. M. L., Purwati, A. A., \& Saputra, E. (2019). Computer Based Test Using Tcexam as an Instrument Learning Evaluation. International Journal of Scientific \& Technology Research, 8(9), 1066-1069

Biantara, I. M. D., Sudana, I. M., Suni, A. F., \& Suryono, S. (2015). Modifikasi Metode Linear Congruential Generators untuk Optimalisasi Hasil Acak. SemNasIF 2015 UPN "Veteran" Yogyakarta

Hangga, A., \& Prabowo, H. E. (2016). Modifikasi Linear Congruential Generator untuk Sistem Pengacakan Soal pada Computer Based Test (CBT). Jurnal Teknik Elektro, 8(2), 47-49

Ichsan, M. (2014). Menutup Celah Ujian Online. http://www.bppk.kemenkeu.go.id/ publikasi/artikel/419-artikelteknologi-informasi/20318menutup-celah-ujian-online

Katti, R. S., Kavasseri, R. G., \& Sai, V. (2010). Pseudorandom Bit Generation Using Coupled Congruential Generators. Circuits and Systems II: Express Briefs, IEEE Transactions 57(3), 203207

Meilani, B. D., Maslu, M., \& Ailik, A. (2016). Aplikasi Random Random Bank Soal Ujian Nasional Sekolah Dasar Menggunakan Metode Linear Congruential Generators (LCG). Seminar Nasional Sains dan Teknologi Terapan IF

Munthe, D. (2014). Implementasi Linier Congruent Method (LCM) pada Aplikasi Tryout SNMPTN. Jurnal Pelita Informatika Budi Darma, 7(2), 111-115
Nasution, S. D. (2013). Penerapan Metode Linier Kongruen dan Algoritma Vigenere Chiper pada Aplikasi Sistem Ujian Berbasis LAN. Jurnal Pelita Informatika Budi Darma 4(1), 94-102

Ramadhan, K., Astuti, L. W., \& Verano, D. A. (2016). Game Edukasi Tebak Gambar Bendera Negara Menggunakan Metode Linear Congruential Generator (Lcg) Berbasis Android. Jurnal Informatika Global, 6(1)

Sofyan, S. (2016). Penerapan Linear COngruential Generators (LCG) Dalam Perancangan Perangkat Lunak Permainan Ken Ken. Jurnal Times, $V(1), 20-22$

Martono, K. T., \& Nurhayati, O. D. (2014). Implementation of Android Based Mobile Learning Appliaction as a Flexible Learning Media. IJSI International Journal of Computer Science, 11(3), 168-174

Bahri, S., Wintolo, H., Honggowibowo, H., \& Anton, S. (2012). Algoritma Random pada Computer Based Test Penerimaan Mahasiswa Baru STTA Yogyakarta. Compiler, 1(2), 157-163 